\title{
Problemas de cálcio na Água de abastecimento de Nova OLINDA - CE
}

\section{Problems of calcium in the water supply to Nova Olinda - CE}

\section{LUIZ ALBERTO RIBEIRO MENDONÇA}

Engenheiro Civil. Doutor em Engenharia Civil/Recursos Hídricos pela UFC. Professor Adjunto do Curso de Engenharia Civil da UFC, Campus Cariri

\section{Marcelo OliVEIRA SANTIAGo}

Químico. Doutor em Química pela Universidade Federal de São Carlos. Professor Adjunto do Curso de Engenharia Civil da UFC, Campus Cariri

\section{HORST FRISCHKORN}

Físico. Dr. rer. nat. em Físico-química pela Universidade de Marburg/Alemanha. Professor Adjunto do Departamento de Engenharia Hidráulica e Ambiental da UFC, Fortaleza

\section{JOSE MARCOS SASAKI}

Físico. Doutor em Física pela Universidade Estadual de Campinas e Pós-doutor pela University of Strathclyde. Professor Adjunto do Departamento de Física da UFC, Fortaleza

Recebido: 30/05/07 Aceito: 15/07/08

\section{RESUMO}

A cidade de Nova Olinda, sul do Estado do Ceará, é abastecida através de quatro poços tubulares profundos que captam num aqǘfero confinado, composto, basicamente, por arenito. $\mathrm{Na}$ área também afloram calcita e gipsita, que são explotadas por mineradoras instaladas dentro da bacia hidrográfica, onde estão três dos quatro poços. Desde 2006, as tubulações de abastecimento de água estão sendo obstruídas por um precipitado folhear, causando prejuízos. Neste trabalho foi feita uma investigação, usando análises químicas, físico-químicas e de raios X e o índice de saturação de calcita (ISC), para estudar as possíveis causas dos precipitados, identificados, basicamente como calcita. As concentrações de cálcio e os ISCs indicaram que o tratamento da água aplicado na desinfecção aumenta a tendência da precipitação de calcita devido o cálcio contido nos produtos químicos usados.

PALAVRAS-CHAVE: Qualidade de água, índice de saturação de calcita, precipitação de calcita.

\section{INTRODUÇÃO}

O município de Nova Olinda, localizado na Região do Cariri, sul do Estado do Ceará, tem área de aproximadamente $284 \mathrm{~km}^{2}$ e encontra-se nas coordenadas geográficas: $7^{\circ} 05^{\prime} 30^{\prime \prime}$ de latitude sul e $39^{\circ} 40^{\prime} 50^{\prime \prime}$ de longitude oeste de Greenwich (IPLANCE, 2007). A população deste município, de aproximadamente 11.500 habitantes, é abastecida pela Companhia de Água e Esgoto do Ceará (CAGECE) através de quatro poços tubulares profundos (Figura 1).

Nesta área encontra-se um planalto sedimentar, a Chapada do Araripe, com altitude média de aproximadamente $850 \mathrm{~m}$, e a depressão sertaneja, com altitude média de aproximadamente $475 \mathrm{~m}$, onde está localizada a cidade de Nova Olinda. O clima entre o planalto e a depressão sertaneja varia, respectivamente, de tropical quente subúmido a tropical quente semi-árido. A temperatura média anual varia de 24 a $26^{\circ} \mathrm{C}$ e a pluviosidade média anual é de aproximadamente $680 \mathrm{~mm}$, com período chuvoso de janeiro a maio (IPLANCE, 2007).

Geologicamente, a Chapada do Araripe é formada, do topo para a base, pelas formaçôes: Exu e Arajara, compostas predominantemente por arenitos, que formam o Sistema Aqüifero Superior da Bacia Sedimentar do Araripe, e Santana, composta predominantemente por gipsita, calcário e níveis argilosos. 
Ao nível regional, abaixo da Chapada, existem as formações geológicas: Rio da Batateira, Abaiara e Missão Velha, compostas predominantemente por arenitos, que formam o Sistema Aqüifero Médio da Bacia Sedimentar do Araripe, o mais importante do Ceará; Brejo Santo, composta predominantemente por argilas e folhelhos argilosos; e Mauriti, composta predominantemente por arenitos silicificados, que formam o Sistema Aqüífero Inferior, que aflora nas bordas da bacia sedimentar (Ribeiro et al, 1996; Ribeiro \& Veríssimo, 1996; Ribeiro, 1995).

No município de Nova Olinda afloram todas as formações geológicas que compóem a Chapada do Araripe e as formações Brejo Santo e Mauriti.

Os poços tubulares que fazem parte do sistema de abastecimento da cidade, explotam águas do Aqüífero Mauriti, composto basicamente por arenito silicificado e confinado por lentes de argila da formação Brejo Santo. As águas explotadas possuem turbidez extremamente baixa, $\mathrm{pH}$ médio de 7,5 e condutividade elétrica média de $753 \mu \mathrm{S} / \mathrm{cm}$. A estratigrafia geológica da área de captação dos poços é mostrada na Figura 2.

Além das águas subterrâneas, para os recursos hídricos na área também contribui uma rede de drenagem intermitente, com alguns rios alimentados por fontes perenes que surgem na encosta da chapada. O principal rio do município é o rio Cariús, que possui afluentes formados de pequenos tributários sem destaques. No abastecimento público utilizam-se apenas as águas subterrâneas.

Desde 2006 as tubulaçôes do sistema de abastecimento de água da cidade, bem como as canalizaçôes residenciais, estão sendo progressivamente obstruídas por um precipitado que se apresenta na forma folhear (Figura 3). Este fenômeno vem causando prejuízos sucessivos à companhia de abastecimento, que é obrigada a substituir as tubulações obstruídas da rede de abastecimento e os manômetros de algumas residências, e aos moradores, que constantemente são surpreendidos pela falta de água e danos às instalações hidráulicas.

Supóe-se que este precipitado seja composto de calcário, um dos minerais que compõe a formação Santana, pois na área existem várias mineradoras que exploram e beneficiam placas de cal-
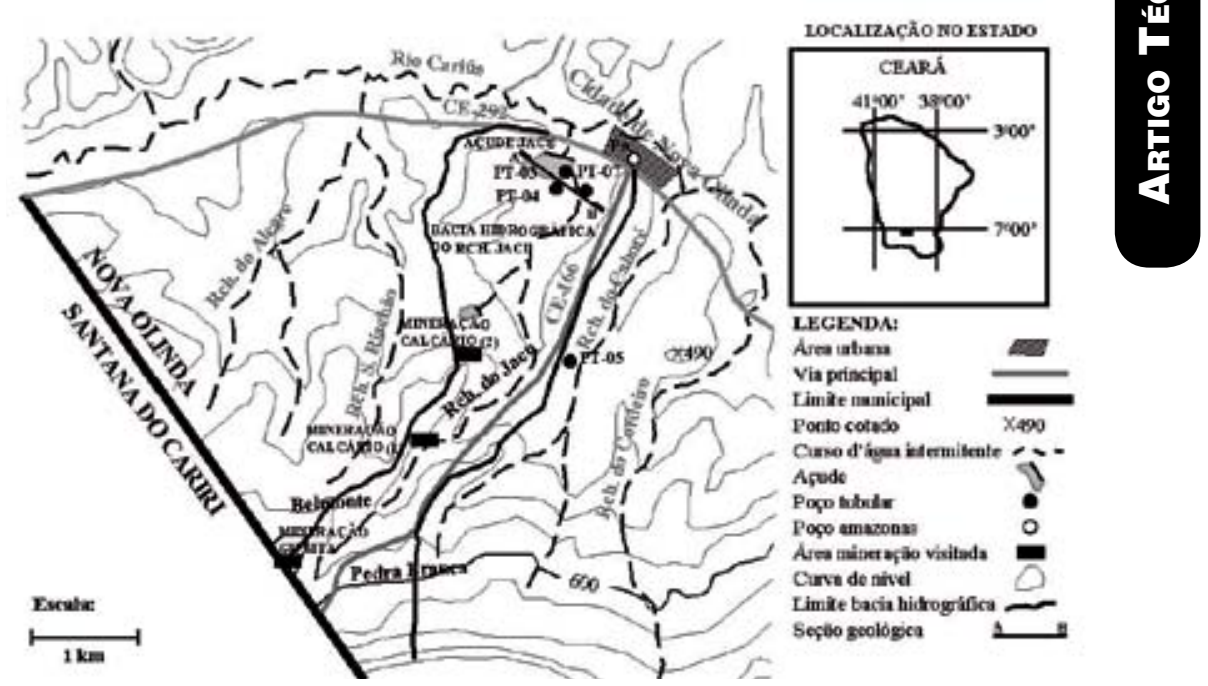

Figura I - Mapa de localização da área

Seçăo AB:

Poço PT-05:
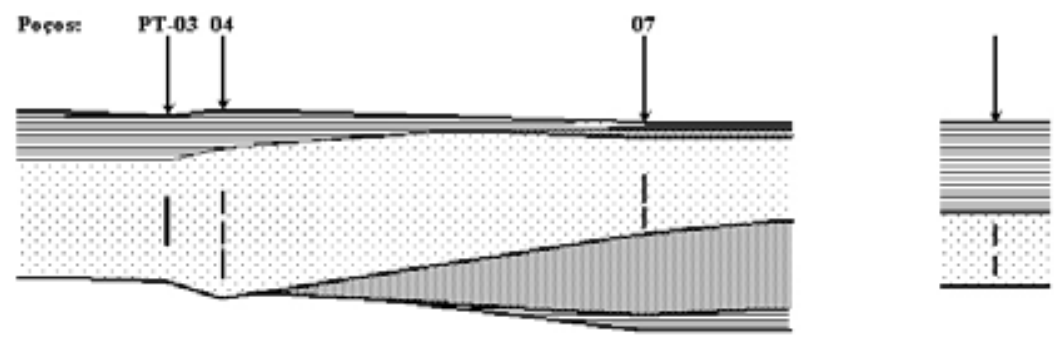

Legenda:

Folhelhos

Arenito silicificado

Eseala:

Arenito argil ose

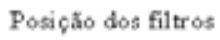

Figura 2 - Estratigrafia geológica da área de captação dos poços (seção AB da Figura I)

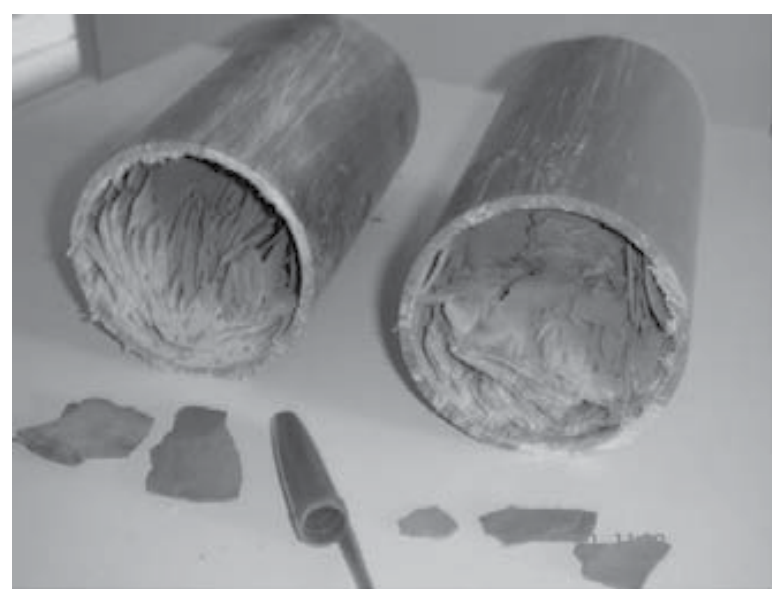

Figura 3 - Tubos obstruídos da rede de abastecimento de água 
cário, que servem como revestimento e piso na construção civil. Além do mais, visualmente, a forma de deposição folhear nas tubulaçôes assemelham-se muito à estrutura folhear das placas de calcário, inclusive com coloração semelhante. Mas, de acordo com a estratigrafia geológica da Figura 2, os poços captam água num aqüífero que não possui calcário na estrutura geológica. A formação Santana, que contém calcário e gesso, encontra-se, segundo a geologia, sobre a formação Brejo Santo que confina o aqüífero Mauriti explotado. Porém, de acordo com a Figura 1, observa-se que boa parte das mineradoras encontra-se dentro da bacia hidrográfica do Riacho do Jacu, onde estão perfurados três dos quatro poços de abastecimento.

Neste trabalho será feita uma investigação, usando medidas químicas e físico-químicas e de caracterização por espectroscopia de raios X, associadas à modelagem matemática do índice de saturação de calcita, visando identificar os elementos que compóem o precipitado das tubulações, os possíveis mecanismos que produzem a precipitação e os estágios de saturação de calcita na água de abastecimento.

Os resultados e discussões extraídos destas análises podem fornecer informaçōes importantes para a gestão do sistema de abastecimento de água de Nova Olinda.

\section{METODOLOGIA}

As concentrações dos íons maiores $\mathrm{Ca}^{2+}, \mathrm{Mg}^{2+}, \mathrm{Na}^{+}, \mathrm{K}^{+}, \mathrm{Cl}^{-}, \mathrm{SO}_{4}{ }^{2-}, \mathrm{HCO}_{3}^{-} \mathrm{e}$ do $\mathrm{NO}_{3}^{-} \mathrm{pH}$ e da condutividade elétrica (CE) das águas dos poços tubulares pertencentes ao sistema de abastecimento de Nova Olinda, bem como de um poço amazonas e de um açude que não fazem parte do sistema, foram determinadas no laboratório da Companhia de Água e Esgoto do Ceará (CAGECE).

As análises químicas, físico-químicas e de raios $\mathrm{X}$ de amostras do precipitado nas tubulaçôes foram feitas respectivamente nos laboratórios da Fundação Núcleo de Tecnologia Industrial (NUTEC) e no Laboratório de Raios X do Departamento de Física da Universidade Federal do Ceará (UFC) em Fortaleza.

O índice de saturação da calcita (ISC), mineral presente na área, foi utilizado na interpretação dos dados hi- droquímicos. Segundo Alberty (1987), o ISC é dado por

$$
\text { ISC }=-\log \mathrm{k}_{\text {cal }}+\log \mathrm{k}_{\mathrm{HCO}_{3}^{-}}+\mathrm{pH}+
$$$$
+\log \mathrm{a}\left(\mathrm{HCO}_{3}^{-}\right)+\log \mathrm{a}\left(\mathrm{Ca}^{2+}\right)
$$

onde: $\mathrm{K}_{\text {cal }}$ é a constante de equilíbrio obtida da equação de dissolução da calcita $\mathrm{CaCO}_{3} \stackrel{\text { Kcal }}{\longleftrightarrow} \mathrm{Ca}^{2+}+\mathrm{CO}_{3}^{2-}, \mathrm{k}_{\mathrm{HCO}_{3}^{-}}$

é a constante de equilíbrio da equação da ionização do íon bicarbona$\mathrm{t}$ o $\mathrm{HCO}_{3}^{-} \stackrel{{ }^{k} \mathrm{HCO}_{3}}{\longleftrightarrow} \mathrm{H}^{+}+\mathrm{CO}_{3}^{2-}, \mathrm{p} \mathrm{H}$ é o potencial hidrogênio iônico e a $\left(\mathrm{HCO}_{\overline{3}} \mathrm{e} \mathrm{Ca}^{2+}\right)$ são as atividades iônicas dos íons $\mathrm{HCO}_{3}^{-} \mathrm{e}^{2+}$, respectivamente.

A atividade iônica de cada íon (a) é expressa pelo produto entre o coeficiente de atividade $\left(\gamma_{i}\right)$ e a concentração molar $\left[\mathrm{A}_{\mathrm{i}}\right]$.

Segundo Alberty (1987), o coeficiente de atividade depende da atividade iônica (I), que é função da interação dos íons envolvidos e da valência ( $z_{i}$ ) e é dado pela equação de Debye-Hückel

$\log C_{i}=-\frac{A\left(z_{i}\right)^{2} I^{1 / 2}}{1+a_{i} B I^{1 / 2}}$

onde: A e B são constantes relacionadas ao solvente, dependentes da pressão e temperatura, $\alpha_{i}$ é uma constante relacionada ao diâmetro efetivo do íon em solução e

$\mathrm{I}=\frac{1}{2} !\left(\mathrm{z}_{\mathrm{i}}\right)^{2} 6 \mathrm{~A}_{\mathrm{i}} @$

Foram adotadas, para uma temperatura de $30^{\circ} \mathrm{C}$ e pressão total de 1 bar, as constantes de equilíbrio - $\log \mathrm{k}_{\text {cal }} \mathrm{e}-\log \mathrm{k}_{\mathrm{HCO}_{3}}$ de respectivamente 8,51 e 10,29 e as constantes para o cálculo das atividades iônicas $\mathrm{A}, \mathrm{B}$ e $\alpha_{\mathrm{i}}$ para os íons $\mathrm{Ca}^{2+}$ e $\mathrm{HCO}_{3}^{-} \mathrm{de}$ respectivamente $0,5130 \mathrm{~L}^{1 / 2} / \mathrm{mol}^{1 / 2}$, $0,3290 \times 10^{-8} \mathrm{~cm}^{-1}, 6,00 \times 10^{8} \mathrm{~cm} \mathrm{~L}^{1 / 2} / \mathrm{mol}^{1 / 2}$ e $4,25 \times 10^{8} \mathrm{~cm} \mathrm{~L}^{1 / 2} / \mathrm{mol}^{1 / 2}$ (Freeze $\&$ Cherry, 1979).

\section{RESULTADOS}

Os dados hidroquímicos das águas amostradas estão listados na Tabela 1 .

A temperatura média das águas subterrâneas da região encontra-se em torno de $30^{\circ} \mathrm{C}$ (Silva, 1996).

As medidas químicas e físico-químicas de amostras do precipitado das tubulações indicaram a presença de 19,97\% de sílica; $2,95 \%$ de alumínio; $1,84 \%$ de ferro; $1,68 \%$ de óxido de magnésio; 39,42\% de óxido de cálcio; e $33,19 \%$ de perda ao fogo a $1.000{ }^{\circ} \mathrm{C}$. As de raios $\mathrm{X}$ reforçaram a indicação da predominância do mineral calcita no precipitado.

\section{DISCUSSÕES}

\section{Evolução temporal das concentrações de cálcio e do ISC}

Durante o decorrer do tempo observa-se, na Tabela 1, um aumento na concentração de cálcio nas águas explotadas pelos poços tubulares. $\mathrm{Na}$ Figura 4a é representada a evolução gradual destas concentrações para as águas explotadas pelos poços tubulares PT03, PT04 e PT07, todos localizados na bacia hidrográfica do Riacho do Jacu. No poço PT05, localizado fora da bacia, as concentrações são praticamente estáveis e bem inferiores a dos demais poços.

$\mathrm{Na}$ Figura $4 \mathrm{~b}$ verifica-se também um aumento drástico entre 2005 e 2006 na água bruta armazenada no reservatório de reunião da estação de tratamento. A água tratada, coletada na estação de tratamento, apresentou uma redução gradual nas concentrações de cálcio a partir de janeiro de 2007 chegando, em março, a um valor inferior ao da água bruta no mesmo mês.

Uma possível explicação para esta redução gradual nas concentrações de cálcio na água tratada seria a precipitação deste elemento após o tratamento.

Para o ISC verifica-se uma evolução conduzindo a água bruta a uma condição de saturação cada vez maior (Figura 5a). No poço tubular PT03, observa-se uma quase estabilização em 1996 e novembro de 2006, e um aumento, em março de 2007; no poço PT04, um aumento de novembro de 2006 para março de 2007; no poço PT05, um aumento, conduzindo a água da subsaturação, em maio de 2005 e novembro de 2006, para um valor próximo ao equilíbrio, em março de 2007; e no poço PT07, de um valor próximo ao equilíbrio, em setembro de 2003, para a saturação, em novembro de 2006. Nestes casos verifica-se um aumento com o tempo na condição de precipitação de calcita das águas de abastecimento da cidade.

$\mathrm{Na}$ Figura $5 \mathrm{~b}$ verifica-se que a água bruta armazenada no reservatório de reunião da estação de tratamento apresentou-se subsaturada em calcita em maio de 2005, saturada em novembro de 2006 e próxima ao equilíbrio em março de 2007. A água tratada apresentou uma redução gradual no ISC, de dezembro de 2006 a março de 2007, porém apresentando valores superiores aos da água bruta. 
Tabela I - Dados hidroquímicos das águas amostradas no município de Nova Olinda. PT: poço tubular; ETA: estação de tratamento de água; PA: poço amazonas; AJ: açude Jacu; CE: condutividade elétrica; ISC: índice de saturação de calcita

\begin{tabular}{|c|c|c|c|c|c|c|c|c|c|c|c|}
\hline \multirow[t]{2}{*}{ Amostra } & \multicolumn{8}{|c|}{ Concentração $(\mathrm{mg} / \mathrm{L})$} & \multirow[t]{2}{*}{$\mathrm{pH}$} & \multirow{2}{*}{$\begin{array}{c}\text { CE } \\
(\mu \mathrm{S} / \mathrm{cm})\end{array}$} & \multirow[t]{2}{*}{ ISC } \\
\hline & $\mathrm{Ca}^{2+}$ & $\mathrm{Mg}^{2+}$ & $\mathrm{Na}^{+}$ & $\mathrm{K}^{+}$ & $\mathrm{Cl}^{-}$ & $\mathrm{SO}_{4}^{2-}$ & $\mathrm{HCO}_{\overline{3}}$ & $\mathrm{NO}_{\overline{3}}$ & & & \\
\hline \multicolumn{12}{|c|}{ Água bruta } \\
\hline РT03 (1996)* & 26,1 & 11,6 & 117,5 & 3,9 & 49,6 & 100,9 & 244,1 & 0,0 & 7,7 & 976 & 0,11 \\
\hline РT07 (19/09/03) & 43,4 & 7,6 & 16,6 & 8,5 & 55,0 & 77,0 & 302,4 & 3,6 & 7,3 & 806 & 0,02 \\
\hline ETA $(12 / 05 / 05)$ & 19,4 & 92,0 & - & - & 90,0 & 154,0 & 364,7 & 0,0 & 7,3 & - & $-0,30$ \\
\hline РT05 (12/05/05) & 9,3 & 52,9 & - & - & 56,4 & 167,0 & 357,4 & 0,0 & 7,7 & - & $-0,15$ \\
\hline ETA $(24 / 11 / 06)$ & 48,5 & 14,5 & - & - & 72,7 & 80,0 & 367,2 & 1,3 & 7,3 & 732,4 & 0,17 \\
\hline РT03 (25/11/06) & 43,0 & 30,5 & - & - & 92,9 & 100,0 & 393,6 & 6,6 & 7,3 & 875,5 & 0,16 \\
\hline РT04 (25/11/06) & 43,0 & 29,1 & - & - & 91,9 & 101,0 & 386,4 & 4,4 & 7,4 & 858,6 & 0,20 \\
\hline РT05 (25/11/06) & 7,8 & 37,5 & - & - & 61,6 & 131,0 & 383,9 & 3,1 & 7,7 & 887,1 & $-0,17$ \\
\hline РT07 (25/11/06) & 64,9 & 3,8 & - & - & 68,6 & 76,0 & 336,0 & 6,2 & 7,3 & 872,6 & 0,26 \\
\hline ETA $(08 / 03 / 07)$ & 43,0 & 25,8 & - & - & 77,7 & 104,0 & 319,2 & 4,9 & 7,3 & 655,9 & 0,05 \\
\hline РT03 (08/03/07) & 84,5 & 13,1 & - & - & 98,9 & 130,0 & 333,6 & 8,9 & 7,4 & 736,7 & 0,47 \\
\hline РT04 (08/03/07) & 76,6 & 19,2 & - & - & 101,9 & 113,0 & 304,8 & 5,8 & 7,6 & 707,2 & 0,61 \\
\hline РТ $05(08 / 03 / 07)$ & 11,7 & 46,5 & - & - & 65,6 & 136,0 & 336,0 & 7,1 & 7,8 & 698,1 & 0,03 \\
\hline PA (12/04/07) & 29,7 & 12,2 & - & - & 108,0 & 85,0 & 396,0 & 0,0 & 6,9 & 461,8 & $-0,44$ \\
\hline $\mathrm{AJ}(12 / 04 / 07)$ & 41,4 & 5,2 & - & - & 17,2 & 19,0 & 100,8 & 14,6 & 7,2 & 204,7 & $-0,52$ \\
\hline \multicolumn{12}{|c|}{ Água tratada } \\
\hline ETA $(11 / 12 / 06)$ & 46,9 & 26,9 & - & - & 84,8 & 46,0 & 319,2 & 4,4 & 7,8 & 752,8 & 0,61 \\
\hline ETA $(09 / 01 / 07)$ & 55,5 & 7,0 & - & - & 75,7 & 52,0 & 355,2 & 0,0 & 7,7 & 540 & 0,61 \\
\hline ETA $(05 / 02 / 07)$ & 83,7 & 16,4 & - & - & 79,7 & 79,0 & 388,8 & 2,7 & 7,1 & 662,3 & 0,21 \\
\hline ETA $(08 / 03 / 07)$ & 24,2 & 36,1 & - & - & 89,8 & 76,0 & 283,2 & 8,9 & 7,7 & 638,4 & 0,19 \\
\hline Rua (08/03/07) & 30,5 & 31,9 & - & - & 82,8 & 122,0 & 283,2 & 8,9 & 7,7 & 649,2 & 0,27 \\
\hline
\end{tabular}

* Medidas obtidas de Silva (1996).

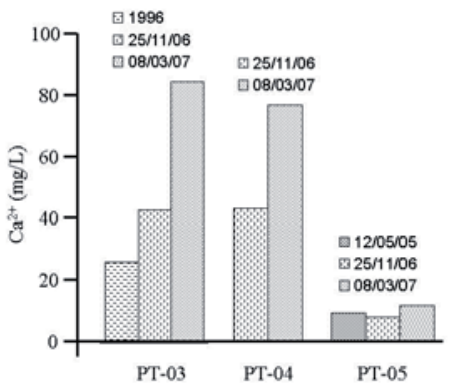

(a)

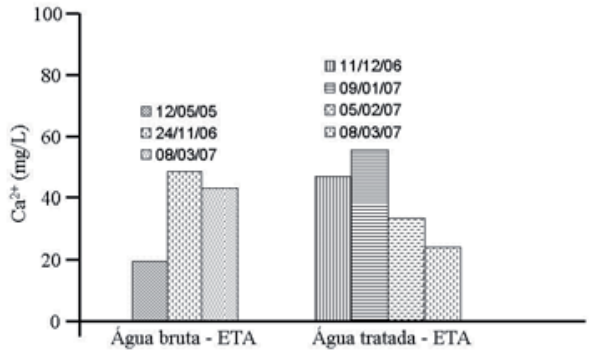

(b)

Figura 4 - Concentrações de cálcio ao longo do tempo nas águas explotadas pelos poços tubulares (a) e nas águas bruta e tratada da estação de tratamento (b) da cidade de Nova Olinda 


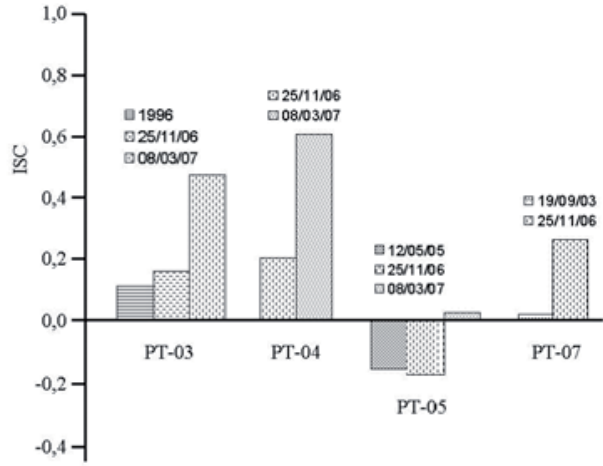

(a)

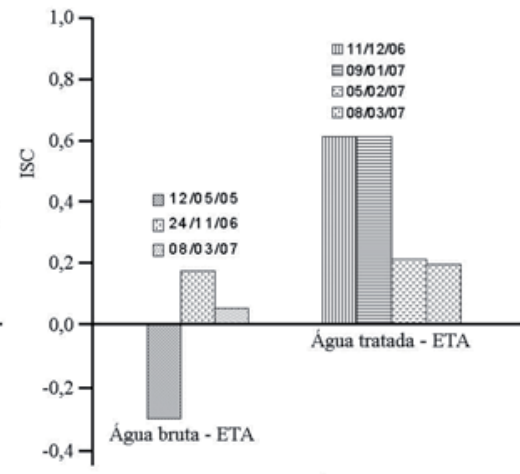

(b)
Figura 5 - Índice de saturação de calcita (ISC) ao longo do tempo nas águas explotadas pelos poços tubulares (a) e nas águas bruta e tratada da estação de tratamento (b) da cidade de Nova Olinda
Os índices calculados para a água tratada com valores superiores aos da água bruta deve-se, possivelmente, ao processo de tratamento da água, que utiliza hipoclorito de cálcio $65 \%$ como desinfetante de água para consumo humano. Este produto possui, além do hipoclorito de cálcio, $35 \%$ de carbonato de cálcio, cloreto de cálcio, hidróxido de cálcio, clorato de cálcio, cloreto de sódio e água. $\mathrm{O}$ aporte de cálcio no tratamento bacteriológico contribui com o aumento do ISC, podendo acelerar a precipitação de calcita na rede de distribuição de água da cidade e nas tubulações residenciais.

As águas coletadas em mananciais que não fazem parte do sistema de abastecimento da cidade, como o poço amazonas, localizado no centro da cidade, e o Açude Jacu, localizado respectivamente a aproximadamente 30, 100 e $400 \mathrm{~m}$ dos poços PT03, PT04 e PT07, possuem concentrações de cálcio na mesma ordem de grandeza das encontradas nos poços tubulares, mas apresentam ISC < 0 (Figura 6).

\section{Composição do material precipitado}

As medidas químicas, físicoquímicas e de raios $\mathrm{X}$ indicaram que o material precipitado nas tubulações é proveniente de reaçôes químicas ocorridas com calcita; mineral este que não compõe a formação Mauriti, onde se encontra o aqüífero explotado, mas que compõe a formação Santana, que também possui gipsita.

A formação Santana aflora a aproximadamente $3 \mathrm{~km}$ da cidade e lá ocorrem várias áreas de mineração de calcário, onde as pedras em forma de placas são serradas para tamanho padrão e o pó resultante da serragem espalha-se livremente. Nestas áreas são encontradas várias fraturas que,

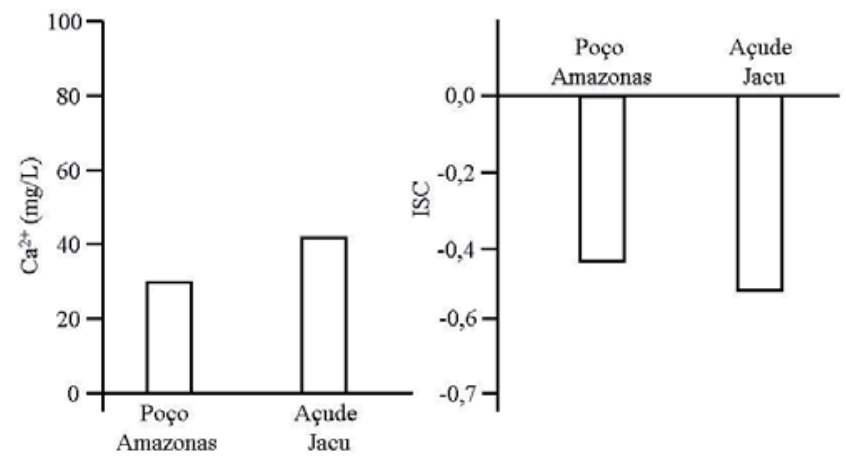

\footnotetext{
Figura 6 - Concentrações de cálcio e índice de saturação de calcita (ISC) em águas coletadas em mananciais que não fazem parte do sistema de abastecimento da cidade de Nova Olinda
}

provavelmente, contribuem com a percolação de águas de lixiviação (Figura 7a). Se estas fraturas forem profundas, ultrapassando a Formação Brejo Santo, o material lixiviado em solução poderá percolar e atingir o aqüífero. Além do mais, em algumas áreas, como se vê no poço PT07 da Figura 2, a Formação Brejo Santo apresenta-se bastante delgada, podendo, inclusive, deixar de existir, favorecendo a recarga direta no aqüífero por águas contendo o material lixiviado em solução.

O material pulverulento, resultante do beneficiamento das placas de calcário nas serrarias (Figura $7 \mathrm{~b}$ ), por possuir partículas de diâmetros bem inferiores ao dos resíduos das minas, poderá contribuir significativamente com o aumento das concentrações de cálcio das águas na área. Estes resíduos também são encontrados na paisagem, que fica coberta por um pó branco nas imediações das indústrias beneficiadoras da gipsita. Materiais pulverulentos possuem partículas de diâmetros extremamente pequenos e consequentemente possuem maior área de contato com a água, acelerando as reações químicas de dissolução.

Mendonça et al (2006), realizaram análises ambientais nestas áreas de mineração e verificaram falta de medidas de controle ou mitigação de impactos ambientais. Eles identificaram várias práticas agressivas ao meio ambiente, decorrentes da lavra sem controle, tais como: desmatamento e queimadas, abertura de estradas e acessos sem controle, desmonte de rochas, remoção dos solos, geração de rejeito e abandono de áreas já mineradas.

Em outro trabalho, Mendonça (2006) observou que a condutividade elétrica da água de um riacho que passa por uma área de mineração de gipsita, em Santana do Cariri, município vizinho à Nova Olinda, passou de $300 \mu \mathrm{S} / \mathrm{cm}$, a montante de uma estrada que dá acesso à área, para $1.500 \mu \mathrm{S} / \mathrm{cm}$, a jusante da mesma, indicando a alta dissolução desse mineral.

\section{Mecanismos de liberação do íon cálcio}

A presença de calcita e gipsita na região condiciona a dissolução destes minerais.

Para a calcita há dois processos possíveis de dissolução, produzindo águas com concentraçôes diferentes 


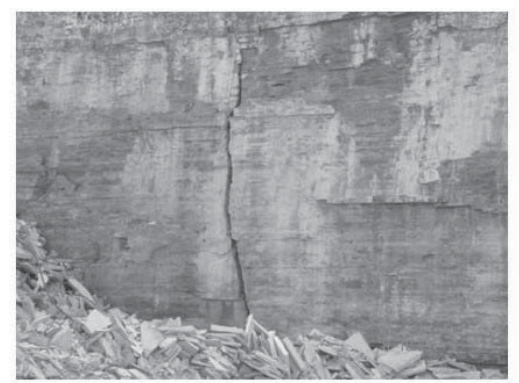

(a)

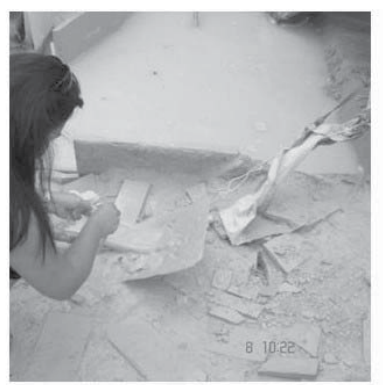

(b)

Figura 7 - Fraturas identificadas na Formação Santana nas áreas de mineração (a) e material pulverulento resultante do beneficiamento das placas de calcário nas serrarias (b)

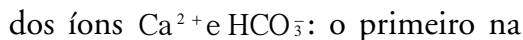
razão molar de 1:1, dado pela reação $\mathrm{CaCO}_{3}+\mathrm{H}^{+} " \mathrm{Ca}^{2+}+\mathrm{HCO}_{3}^{-}$; e o segundo na razão de $1: 2$, dado pela reação $\mathrm{CaCO}_{3}+\mathrm{H}_{2} \mathrm{CO}_{3}+\mathrm{H}^{+}+\mathrm{HCO}_{3}^{-} "$

$$
\text { " } \mathrm{Ca}^{2+}+2 \mathrm{HCO}_{3}^{-} \text {. }
$$

A solubilidade da calcita é de $100 \mathrm{mg} / \mathrm{L}$ para $\mathrm{pH} 7$, temperatura de $25^{\circ} \mathrm{C}$ e pressão total de 1 bar (Plummer et al, 1978).

A Figura 8 a mostra as concentrações de cálcio versus bicarbonatos, em meq/L, e as funções $\mathrm{rCa}^{2+}=\mathrm{rHCO}_{\overline{3}} \mathrm{e} \mathrm{rCa}^{2+}=2 \mathrm{rHCO}_{3}$

representam os limites dos processos de dissolução. Observa-se que os pontos não apresentam correlação e, com exceção da amostra do Açude Jacu, encontram-se afastados do espaço entre as retas, que representa possíveis processos de dissolução da calcita. A grande maioria dos pontos encontra-se abaixo da reta $\mathrm{rCa}^{2+}=2 \mathrm{rHCO}_{3}^{-}$, indicando que há excesso de $\mathrm{HCO}_{3}^{-}$, nas amostras, provavelmente proveniente de reaçóes de troca de sódio, adsorvido nas argilas, pelo cálcio e magnésio em solução na água.

Segundo Thorstenson et al (1979) e Hederson (1985), o cálcio e o magnésio trocáveis com o sódio da argila, produzem elevação de sódio e de bicarbonato na água de acordo com as reações

$$
\begin{aligned}
& \mathrm{CaCO}_{3}+\mathrm{H}_{2} \mathrm{CO}_{3}+2 \mathrm{NaX} * \mathrm{CaX}+ \\
& +2 \mathrm{Na}^{+}+2 \mathrm{HCO}_{3}^{-} \\
& \mathrm{e} \\
& \mathrm{CaMg}\left(\mathrm{CO}_{3}\right)_{2}+\mathrm{H}_{2} \mathrm{CO}_{3}+\mathrm{NaX} \text { * } \\
& \text { * } \mathrm{Ca}^{2+} \mathrm{CO}_{3}^{2-}+2 \mathrm{HCO}_{3}^{-} 2 \mathrm{Na}^{+}+\mathrm{MgX} . \\
& \quad \mathrm{A} \text { Figura } 9 \text { mostra o triangulo de } \\
& \text { ânions do Diagrama de Piper indicando } \\
& \text { a predominância de águas bicarbonatadas, } \\
& \text { confirmando o excesso de bicarbonato nas } \\
& \text { águas do sistema de abastecimento. }
\end{aligned}
$$

Outra contribuição de íons cálcio, acompanhada da contribuição de íons sulfato, é a dissolução de gipsita, expressa pela equação

$$
\begin{aligned}
& \mathrm{H}_{2} \mathrm{O}+\mathrm{CO}_{2}+\mathrm{CaSO}_{4} \cdot 2 \mathrm{H}_{2} \mathrm{O} " \mathrm{H}^{+}+ \\
& +\mathrm{HCO}_{3}^{-}+\mathrm{Ca}^{2+}+\mathrm{SO}_{4}^{2-}+2 \mathrm{H}_{2} \mathrm{O}
\end{aligned}
$$

produzindo águas com razão iônica entre $\mathrm{Ca}^{2+} \mathrm{eSO}_{4}^{2-}$ e de $1: 1$, com solubilidade de $2100 \mathrm{mg} / \mathrm{L}$ para $\mathrm{pH} 7$, temperatura de $25^{\circ} \mathrm{C}$ e pressão de 1 bar (Freeze \& Cherry, 1979).

A Figura 8b mostra que os íons sulfato presentes nas águas do sistema de abastecimento são originados da dissolução da gipsita, um dos minerais que compóem a formação Santana. Os pontos localizados nas proximidades $\mathrm{da}$ reta $\mathrm{rCa}^{2+}=\mathrm{rHCO}_{3}$, representam a contribuição de cálcio e sulfato proveniente da dissolução da gipsita; os pontos circulados, localizados abaixo da reta, representam uma baixa concentração de cálcio e uma excessiva concentração de sulfato, sugerindo uma possível redução de cálcio por troca iônica com as argilas; os pontos ajustados à reta $\mathrm{rCa}^{2+}=\mathrm{rSO}^{2-}+1,65$, paralela à reta $\mathrm{rCa}^{2+}=\mathrm{rHCO}^{-}$, representam a contribuição do sulfato proveniente da gipsita, acrescida de um aporte de cálcio de 1,65 meq/L, proveniente da dissolução de calcita e, no caso das águas tratadas, possivelmente, pela contribuição resultante da desinfecção da água.

\section{Análise do risco de precipitação da calcita}

A Figura 10 mostra os gráficos de correlação entre as concentrações de cálcio, em mg/L, e os ISCs de águas bruta e fora do sistema de abastecimento (a) e de água tratada (b).
Na Figura 10a, as amostras de águas coletadas fora do sistema de tratamento não participam da reta de correlação, por não apresentarem o mesmo comportamento da água bruta, que é captada em horizontes mais profundos do aqüífero.

Praticamente não existe interação entre as águas do Açude Jacu (que possui condutividade elétrica de $205 \mu \mathrm{S} / \mathrm{cm}$ ) e as águas subterrâneas captadas pelos poços tubulares PT03 (com condutividade elétrica média de $863 \mu \mathrm{S} / \mathrm{cm}$ ), PT04 (com $783 \mu \mathrm{S} / \mathrm{cm}$ ) e PT07 (com $839 \mu \mathrm{S} / \mathrm{cm}$ ), pois os filtros dos mesmos estão instalados no Aqüífero Mauriti, que é confinado por espessos folhelhos argilosos da formação Brejo Santo.

Já o poço amazonas (com condutividade elétrica de $462 \mu \mathrm{S} / \mathrm{cm}$ ), que capta na camada mais superficial do Aqüífero Mauriti, apresenta água com características bem mais diferenciadas das dos poços tubulares que, apesar de estarem relativamente próximos, possuem condutividades elétricas bem superiores. Como os filtros dos poços tubulares são bem mais profundos, os mesmos estão captando águas cujas áreas de recarga são mais distantes e onde, possivelmente, estão ocorrendo impactos ambientais que favorecem o enriquecimento de cálcio.

A reta de correlação das águas bruta (Figura 10a) e tratada (Figura 10b), apresentam: coeficientes de correlação (R) de, respectivamente, $0,8883 \mathrm{e}$ 0,9411 ; e coeficientes angulares (s) de, respectivamente, 0,0089 e 0,0158 .

Como a reta representativa da água tratada possui coeficiente angular superior ao da água bruta, a mesma poderá atingir o equilíbrio (ISC $=0$ ) e a saturação (ISC > 0) mais rapidamente e com concentrações de cálcio menores que a da água bruta. De acordo com as retas, a água tratada atingiria o equilíbrio com uma concentração de aproximadamente $14 \mathrm{mg} / \mathrm{L}$, enquanto que a água bruta atingiria com aproximadamente $28 \mathrm{mg} / \mathrm{L}$. Assim, verifica-se uma maior vulnerabilidade à precipitação de calcita na água tratada do que na água bruta. Desta forma, a utilização, no tratamento da água, de substancias desinfetantes que possuem cálcio na composição, poderá acelerar o processo de deposição da calcita.

\section{CONCLUSÕES}

As concentrações de cálcio das águas brutas do sistema de abastecimen- 


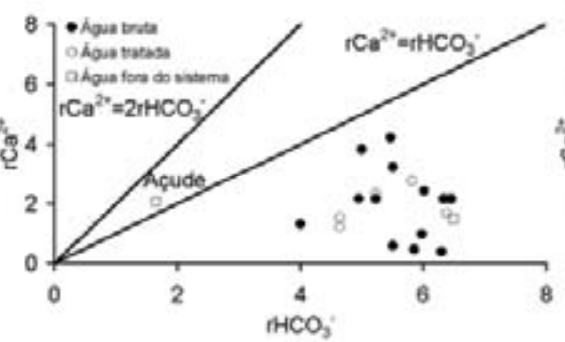

(a)

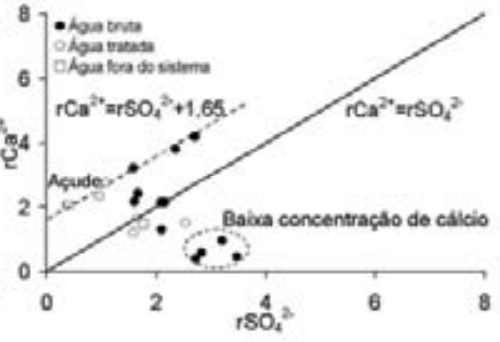

(b)

Figura 8 - $\mathrm{rCa}^{2}+$ vs. $\mathrm{rHCO}_{3}^{-}$(a) e $\mathrm{rCa}^{2}+$ vs. $\mathrm{rSO}_{4}^{2-}$ (b) de amostras de águas bruta, tratada e coletada fora do sistema de abastecimento da cidade de Nova Olinda

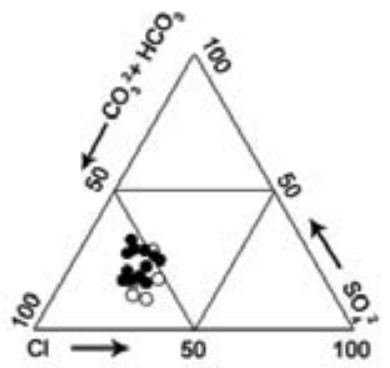

- Água bruta

- Água tratada

Figura 9 - Triangulo de ânions do

Diagrama de Piper para o sistema de abastecimento da cidade de Nova Olinda

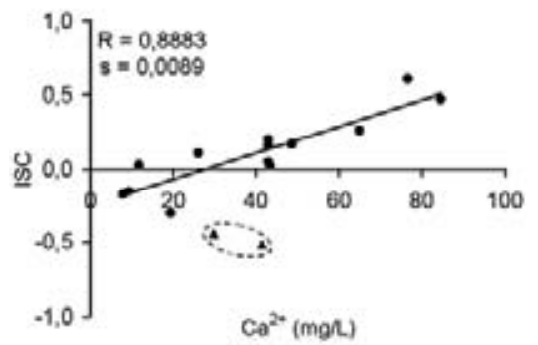

(a)

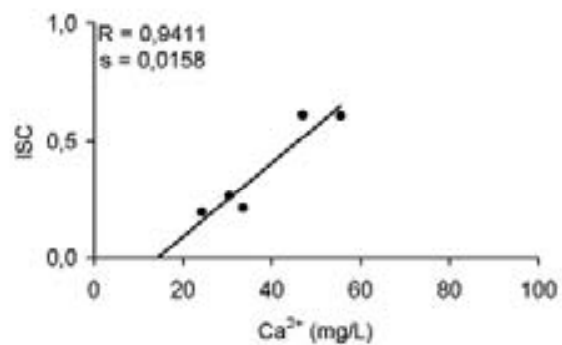

(b)

Figura 10 - ISC vs. concentração de cálcio de amostras de águas brutas e fora do sistema de abastecimento (a) e de água tratada (b)

to d'água de Nova Olinda, apresentaram aumento desde 1996, enquanto a água tratada, apresentou uma redução gradual, chegando a um valor inferior ao da água bruta. Esta redução, contrapondo-se a evolução da água bruta, é explicada pela precipitação deste elemento após o tratamento.

Os índices de saturação de calcita das águas brutas apresentaram uma elevação entre 1996 e 2006, enquanto a água tratada apresentou uma redução, porém, ainda apresentando valores superiores aos da água bruta. Estes valores elevados na água tratada devem-se, pos- sivelmente, ao processo de tratamento da água, que utiliza hipoclorito de cálcio 65\% como desinfetante de água para consumo humano.

As águas coletadas em mananciais que não fazem parte do sistema de abastecimento da cidade, possuem concentrações de cálcio na mesma ordem de grandeza das encontradas nos poços tubulares, mas apresentam-se subsaturadas em calcita.

As medidas químicas e físicoquímicas e de raios $\mathrm{X}$ de amostras do precipitado em tubulaçóes, indicaram a predominância de óxido de cálcio e do mineral calcita. Mineral este que compõe a formação Santana, que aflora no município e que também possui gipsita.

As correlações lineares entre as concentraçôes de cálcio e os índices de saturação de calcita das amostras de águas brutas e tratadas mostraram que a água tratada poderá atingir o equilíbrio $(\mathrm{ISC}=0)$ e a saturação (ISC $>0$ ) mais rapidamente e com concentrações de cálcio menores que a da água bruta. A água tratada atingiria o equilíbrio com uma concentração de aproximadamente $14 \mathrm{mg} / \mathrm{L}$, enquanto que a água bruta atingiria com aproximadamente $28 \mathrm{mg} / \mathrm{L}$. Assim, verifica-se um maior risco de precipitação de calcita na água tratada do que na água bruta, indicando que a utilização, no tratamento da água, de substancias desinfetantes que possuem cálcio na composição, poderá acelerar o processo de deposição da calcita na tubulação de abastecimento.

\section{AGRADECIMENTOS}

Os autores agradecem à Companhia de Água e Esgoto do Estado do Ceará - CAGECE pelas análises químicas e físico-químicas das águas.

\section{REFERÊNCIAS}

ALBERTY, R. A. Eletrochemical equilibria. In: PHYSICAL CHEMISTRY. 7 ed. Singapore: Wiley, p. $306-19,1987$.

FREEZE, R. A.; CHERRY, J. A. Groundwater. New Jersey. Englewood Cliffs, Prentice Hall, 604 p, 1979.

HEDERSON, T. Geochemistry of groundwater in two sandstone aquifer systems in the Northern Great Plains in parts of Montana and Wyoming. U. S. Geol. Surv, Prof. Paper 1402-C, 84 p, 1985.

IPLANCE - Fundação Instituto de Pesquisa e Informação do Ceará, Perfil Básico Municipal, 2004. Disponível em: <http://www.iplance.ce.gov.br>. Acesso: abril/2007.

MENDONÇA, L. A. R. (Coordenador). Diagnóstico ambiental preliminar de áreas de mineração de calcário nos municipios de Santana do Cariri, Nova Olinda, Farias Brito e Altaneira, no Sul do Estado do Ceará. Juazeiro do Norte - CE: CENTEC (Instituto Centro de Ensino Tecnológico), 40 p, 2006.

MENDONÇA, L. A. R. et al. Análise ambiental de áreas de mineração de calcário na Chapada do Araripe no sul do Estado do Ceará. In: VIII SIMPÓSIO ÍTALO BRASILEIRO DE ENGENHARIA SANITÁRIA E AMBIENTAL, Fortaleza. Anais... Rio de Janeiro: ABES, Meio digital. 2006.

PLUMMER, L. N.; WIGLEY, T. M. L., PARKHURST, D. L. The kinetics of calcite dissolution in $\mathrm{CO}_{2}-$ water systems at $5^{\circ}$ to $60^{\circ} \mathrm{C}$ 
and 0.0 to $1.0 \mathrm{~atm} \mathrm{CO}_{2}$. Am. J. Sci., v. 278, p. $179-216,1978$.

RIBEIRO, J. A. Avaliação ambiental da Região do Cariri. In: PROJETO AVALIAÇĀO AMBIENTAL DA REGIÃO DO CARIRI - AMCARI. Série Recursos Minerais. Fortaleza: CPRM, v. 5, 13 p, 1995.

RIBEIRO, J. A.; VERÍSSIMO, L. S. Recursos hidricos e minerais do município de Barbalha-CE. In: PROJETO AVALIAÇĀO AMBIENTAL DA REGIÃO DO CARIRI - AMCARI. Série Ordenamento Territorial. Fortaleza: CPRM, v. 2, 50 p, 1996.

RIBEIRO, J. A. et al. Diagnóstico mineral da Região do Cariri. In: PROJETO AVALIAÇÃO AMBIENTAL DA REGIÃO DO CARIRI - AMCARI. Série Recursos Minerais. Fortaleza: CPRM/ DNPM, v. 7, 42 p, 1996.

SILVA, C. M. S. V. Modelo fenomenológico para a circulação de água na bacia sedimentar do Cariri com base em isótopos e hidroquimica. $162 \mathrm{f}$. Tese (Doutorado em Física) - Departamento de Física, Universidade Federal do Ceará, Fortaleza. 1996.

THORSTENSON, D. C.; FISHER, D. W.; CROFT, M. G. The geochemistry of the Fox Hills-basal hell creek aquifer in Southwestern North Dakota and Northwestern South Dakota. Water Resources Res., v. 15, p. 1479 - 98, 1979.

\section{Endereço para correspondência:}

Luiz Alberto Ribeiro Mendonça Curso de Engenharia Civil Campus da UFC-Cariri Av. Tenente Raimundo Rocha s/ $n^{\circ}$ Bairro Universitário 63000-000 Juazeiro do Norte - CE - Brasil

Tel.: (88) 3572-1329

E-mail: larm@ufc.br 